\title{
PERANCANGAN SOP AUDIT INTERNAL BERDASARKAN INTEGRASI ISO 9001:2015 (KLAUSUL 9.2) DAN ISO 14001:2015 (KLAUSUL 9.2) DENGAN MEMPERTIMBANGKAN RISIKO MENGGUNAKAN METODE BENCHMARK DI CV XYZ
}

\author{
${ }^{1}$ Shifa Khairunnisa, ${ }^{2}$ Sri Widaningrum, ${ }^{3}$ Heriyono Lalu \\ 1,2,3Program Studi Teknik Industri, Fakultas Rekayasa Industri, Telkom University \\ ${ }^{1}$ shifa.khairunnisa@gmail.com, ${ }^{2}$ swidaningrum@telkomniversity.ac.id, ${ }^{3}$ heriyonolalu@telkomuniversity.ac.id
}

\begin{abstract}
Abstrak-CV XYZ adalah perusahaaan yang bergerak di bidang manufaktur yang menerapkan ISO 9001:2008 dan akan menerapkan ISO 9001:2015 dan 14001:2015 karena perubahan standar ISO serta dalam upaya perbaikan berkelanjutan di CV XYZ. Perbaikan berkelanjutan dapat didukung oleh keberhasilan proses audit internal. Pada penelitian terdahulu dihasilkan SOP audit internal berdasarkan integrasi standar ISO 9001:2008 dan 14001:2004 sehingga perlu diperbaharui karena perubahan standar ISO dan agar sesuai dengan kondisi dan kebutuhan perusahaan saat ini. Hal ini mendasari perancangan SOP audit internal berdasarkan ISO 9001:2015 Klausul 9.2 dan ISO 14001:2015 Klausul 9.2 yang telah mempertimbangkan risiko melalui metode benchmarking terhadap perusahaan yang telah mengimplementasikan proses audit internal secara continue. Perancangan SOP diawali dengan mengintegrasikan ISO 9001:2015 Klausul 9.2 dengan ISO 14001:2015 Klausul 9.2 sehingga didapatkan requirement audit internal terintegrasi sebagai acuan perancangan proses bisnis audit internal hasil benchmarking menjadi proses bisnis audit internal sesuai requirement integrasi. Selanjutnya dilakukan risk assessment pada proses bisnis tersebut sehingga menghasilkan risk register yang menjadi input pada proses perancangan SOP sehingga dihasilkan SOP audit internal berdasarkan ISO 9001:2015 Klausul 9.2 dan 14001:2015 Klausul 9.2 dengan mempertimbangkan risiko. Hasil penelitian ini telah terverifikasi memenuhi requirement ISO 9001:2015 dan 14001:2015, sesuai kebutuhan CV XYZ serta telah mengantisipasi risiko kegagalan proses audit internal di CV XYZ. Manfaat penelitian ini adalah CV XYZ memiliki SOP audit internal yang dapat menjamin proses audit internal dilaksanakan secara efektif.
\end{abstract}

Kata kunci: SOP, benchmarking, ISO 9001:2015, ISO 14001:2015, audit

\section{PENDAHULUAN}

Kualitas merupakan sesuatu yang menjadi kebutuhan dan keinginan konsumen. Definisi kualitas tersebut saat ini telah menjadi fokus utama bagi perusahaan untuk selalu memenuhi kebutuhan pelanggan agar dapat bertahan dalam era persaingan yang semakin ketat. Kualitas produk yang baik berasal dari proses yang berkualitas baik. Proses yang berkualitas baik didapatkan dari perbaikan secara terus menerus (continuous improvement) yang dilakukan melalui penerapan sistem menajemen mutu untuk mengatur dan menjamin konsistensi proses dan kesesuaian produk terhadap kebutuhan dan spesifikasi [1]. Penerapan sistem manajemen mutu dapat dilakukan dengan mengacu pada standar internasional sistem manajemen yang berlaku saat ini. Standar yang pada umumnya perlu dimiliki perusahaan untuk mencapai sistem manajemen yang baik yaitu standar internasional ISO 9001 yang mengatur sistem manajemen mutu perusahaan dan standar internasional ISO 14001 yang mengatur sistem manajemen lingkungan perusahaan [1].

$\mathrm{CV}$ XYZ adalah perusahaaan yang bergerak dalam bidang manufaktur untuk sepeda motor CV XYZ adalah perusahaaan yang bergerak dalam bidang manufaktur yang menghasilkan produk berupa mould, press tool, jig \& fixture dan spare part atau suku cadang untuk kendaraan bermotor khususnya sepeda motor yang telah menerapkan SMM berbasis ISO 9001:2008 yang akan menerapkan SMM dan SML berbasis ISO 9001:2015 dan 14001:2015 yang karena tuntutan perubahan standar ISO yang berlaku saat ini. Perubahan yang paling signifikan terletak pada risk based thinking yang harus dilakukan perusahaan sebagaimana disebutkan pada standar ISO 9001:2015 dan standar ISO 14001:2015 klausul 6.1 mengenai tindakan untuk menangani risiko dan peluang. Pada klausul tersebut dinyatakan bahwa organisasi disyaratkan untuk mempelajari berbagai risiko dengan mempertimbangkan berbagai issue, baik internal maupun eksternal. Standar ISO 9001:2015 dan ISO 14001:2015 tersebut selanjutnya dapat dintegrasikan menjadi sebuah sistem manajemen terintegrasi. Pengintergrasian sistem manajeman dilakukan agar penerapanya pada perusahaan menjadi lebih efisien. Penerapan sistem manajemen terintegrasi berbasis ISO 
9001:2015 dan ISO 14001:2015 dilakukan dalam upaya melaksanakan perbaikan berkelanjutan SMM dan SML di CV XYZ yang bertujuan untuk menjaga kredibilitas perusahaan dan kepuasan pelanggan [2] yang merupakan perusahaan otomatif terkemuka di Indonesia. Dalam hal ini, perusahaan tersebut telah memiliki sistem manajemen mutu dan lingkungan yang berstandar internasional.

Perbaikan berkelanjutan dapat didukung oleh keberhasilan proses audit internal diperusahaan. Audit adalah serangkaian kegiatan yang sistematis, independen, dan terdokumentasi untuk memperoleh bukti audit (audit evidence) dan mengevaluasinya secara objektif untuk menentukan sejauh mana kriteria audit (audit criteria) terpenuhi. Adapun audit internal atau disebut juga fist party audit yaitu kegiatan yang dilakukan oleh organisasi itu sendiri, atau atas nama, untuk peninjauan ulang manajemen dan keperluan internal lainnya seperti mengkonfirmasi efektivitas dari sistem manajemen mutu atau untuk mendapatkan informasi untuk perbaikan sistem manajemen [1]. Pelaksanaan audit internal didukung dengan pernyataan pada standar ISO 9001:2015 klausul 9.2 dan standar ISO 14001:2015 klausul 9.2 yang mengharuskan organisasi untuk melakukan audit internal. Pada ISO 9001:2015, audit internal diatur dalam klausul 9.2 yang menjelaskan bahwa perusahaan harus melakukan audit internal pada selang waktu terencana untuk menentukan apakah sistem manajemen mutu memenuhi pengaturan yang direncanakan pada persyaratan sistem manajemen mutu ditetapkan perusahaan [3]. Sedangkan Pada ISO 14001:2015, audit internal diatur dalam klausul 9.2 yang menjelaskan bahwa organisasi harus memastikan bahwa audit internal terhadap sistem manajemen lingkungan dilaksanakan pada jangka waktu yang direncanakan untuk menentukan apakah sistem manajemen lingkungan memenuhi pengaturan yang direncanakan untuk manajemen lingkungan, telah diterapkan dan dipelihara untuk menyediakan informasi hasil audit bagi manajemen [4]. Tidak adanya pelaksanaan audit internal akan berdampak pada tidak dapat dilakukan pengukuran efektivitas sistem manajemen mutu perusahaan yang selanjutnya akan mengakibatkan tidak terdapat pelaksanaan tindakan korektif yang tepat sehingga pelaksanaan (continuous improvement) di perusahaan tidak berjalan yang berdampak pada kelangsungan perusahaan di masa depan.

Pada penelitian terdahulu telah dihasilkan SOP audit internal berdasarkan integrasi standar ISO 9001:2008 dan 14001:2004 [2][5][6] sehingga perlu diperbaharui dengan standar ISO 9001:2015 dan ISO 14001:2015 yang terintegrasi karena SOP hasil penelitian terdahulu belum mempertimbangkan risiko yang dapat mengakibatkan kegagalan proses audit internal di CV XYZ seperti yang saat ini terjadi. Hal ini menjadi dasar perancangan SOP audit internal. Sehingga SOP audit internal yang diusulkan memenuhi requirement ISO 9001:2015 dan ISO 14001:2015 dan sesuai kebutuhan CV XYZ serta dapat mengantisipasi risiko yang akan mengakibatkan kegagalan pada proses audit internal di CV XYZ dan dapat dimplementasikan secara efektif.

Penelitian ini bertujuan untuk membuat requirement audit internal yang terintegrasi, risk register proses audit internal sehingga menghasilkan SOP audit internal yang telah berdasarkan requirement terintegrasi dan telah mempertimbangkan risiko.

\section{METODE PENELITIAN}

Metode penelitian menjelaskan alur kerja dan aliran variabel yang digunakan dalam penelitian untuk menghasilkan SOP audit internal berdasarkan integrasi ISO 9001:2015 klausul 9.2, ISO 14001:2015 klausul 9.2 di CV XYZ dengan mempertimbangkan risiko sehingga dapat menjamin terlaksananya proses audit internal di CV XYZ secara efektif seperti pada Gambar 1. Penelitian diawali dengan proses mengintegrasikan klausul yang berisi persyaratan audit internal yaitu klausul 9.2 pada standar ISO 9001:2015 dan ISO 14001:2015 yang berisi persyaratan-persyaratan audit internal sehingga menghasilkan sebuah requirement proses audit internal yang telah terintegrasi. Pada saat yang sama juga dilakukan proses benchmarking proses bisnis audit internal terhadap perusahaan partner benchmark untuk mendapatkan proses bisnis yang lebih baik [7].

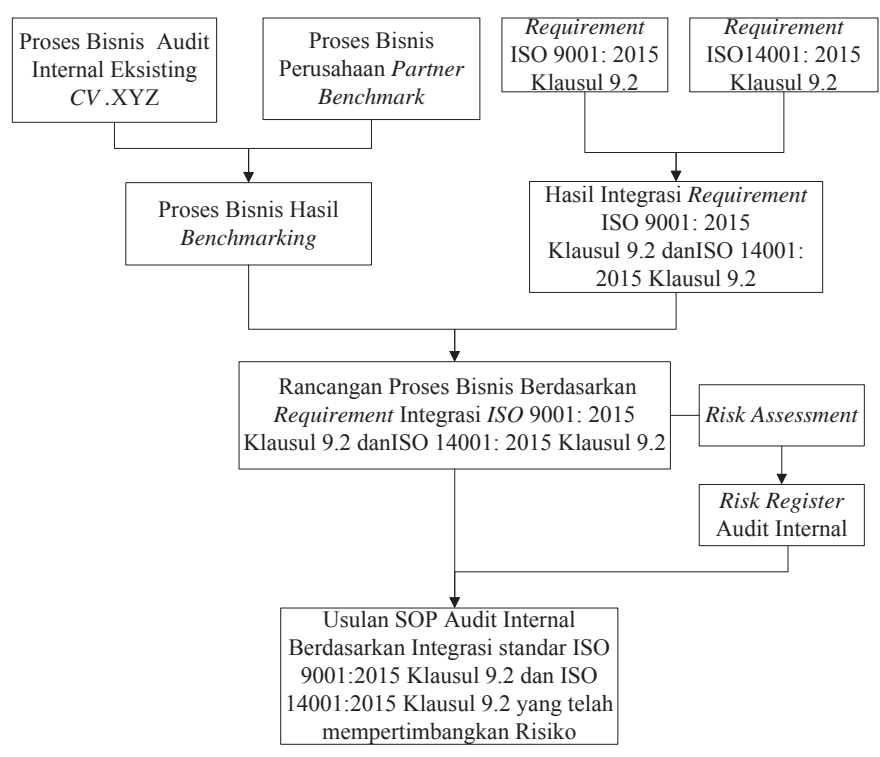

Gambar 1 Metode Penelitian

Proses bisnis hasil benchmarking kemudian dianalisis kesesuaiannya dengan requirement audit internal hasil integrasi ISO 9001:2015 klausul 9.2 dan ISO 14001:2015 klausul 9.2 sehingga didapatkan proses bisnis audit internal yang telah berdasarkan requirement audit internal hasil integrasi. Proses bisnis tersebut kemudian dijadikan input untuk melakukan risk assessment audit internal untuk mengetahui risiko yang mungkin muncul dalam proses audit internal.

Proses risk assessement dilakukan melalui beberapa tahapan yang terdiri dari tahap yaitu tahap identifikasi risiko yaitu tahap menentukan risiko pada setiap aktivitas dari proses audit internal yang sudah sesuai dengan requirement audit internal hasil integrasi ISO 9001:2015 dan 14001:2015, tahap analisis risiko yaitu tahap untuk menentukan nilai dari risiko tersebut. Penilaian dilakukan dengan menentukan seberapa sering risiko tersebut timbul (likelihood) dan seberapa besar dampaknya terhadap organisasi (severity), tahap evaluasi risiko yaitu tahap menentukan rating risiko berdasarkan hasil penilaian risiko pada analisis risiko yang telah dilakukan. Rating risiko ini digunakan untuk menentukan risiko yang menjadi prioritas untuk ditangani, tahap penanganan risiko yaitu tahap pemberian respon atau 
penanggulangan risiko. Penanganan risiko ini dilakukan pada risiko yang mempunyai rating high pada tahap evaluasi risiko.

Proses risk assessment tersebut akan menghasilkan risk register audit internal CV XYZ. Risk register yang dihasilkan pada proses risk assessment akan menjadi masukan pada proses perancangan SOP audit internal CV XYZ sehingga usulan SOP audit internal yang diberikan telah sesuai dengan requirement audit internal hasil integrasi ISO 9001:2015 klausul 9.2 dan ISO 14001:2015 klausul 9.2 dan telah mempertimbangkan risiko sebagaimana yang disyaratkan oleh standar ISO 9001:2015 dan ISO 14001:2015.

Perancangan SOP audit internal diawali dengan tahap analisis hasil rancangan proses bisnis yang disusun berdasarkan requirement dan risk register. Pada tahap ini risk register yang didalamnya terdapat penanganan risko akan memberikan rekomendasi tindakan untuk mengantisipasi risiko baik berupa penambahan aktivitas pada proses bisnis audit internal berdasarkan requirement yang telah disusun atau ketentuan tambahan dalam melaksanakan sebuah aktivitas pada proses audit internal. Tahap ini pada dasarnya adalah menggabungkan proses bisnis yang sudah disusun berdasarkan requirement meliputi aktivitas beserta ketentuanya dengan tindakan penanganan risiko menjadi satu kesatuan yang utuh sehingga dapat dihasilkan SOP proses audit internal yang lebih baik berdasarkan requirement dengan mempertimbangkan risiko untuk dapat mencegah kegagalan proses audit internal di CV XYZ. Pada proses ini juga diidentifikasi dokumen yang dibutuhkan pada tiap aktivitas dalam proses audit internal

\section{HASIL DAN PEMBAHASAN}

A. Requirement Audit Internal Hasil Integrasi

Requirement audit internal pada standar ISO 9001:2015 dan

ISO 14001:2015 diintegrasikan kemudian ditemukan gap persyaratan audit internal antara kedua standar tersebut sehingga dihasilkan sebuah requirement audit internal baru yang telah mencakup persyaratan audit internal yang disyaratkan pada kedua standar yaitu ISO 9001:2015 dan ISO 14001:2015. Berikut merupakan hasil integrasi persyaratan audit internal ISO 9001:2015 dan ISO 14001:2015:

1. Sub Klausul 9.2.1 proses audit internal umum

Organisasi harus melakukan audit internal pada selang waktu terencana agar dapat menilai sistem manajemen perusahaan :

a. Memenuhi persyaratan manajemen mutu dan manajemen ligkungan serta persyaratan ISO 9001:2015 dan ISO 14001:2015

b. Diterapkan dan dipelihara secara efektif

2. Sub Klausul 9.2.1 kewajiban organisasi :

c. merencanakan, menetapkan, menerapkan, dan memelihara program audit, termasuk frekuensi, metode, tanggung jawab, perencanaan dan pelaporan audit, dengan mempertimbangkan sasaran mutu dan lingkungan pada proses-proses yang dilakukan, pentingnya proses, umpan balik pelanggan, perubahan yang berdampak pada organisasi dan hasil audit sebelumnya

d. menentukan kriteria audit dan lingkup audit

e. menseleksi auditor dan menjamin objektivitasdan ketidaberpihakan proses audit

f. memastikan bahwa hasil audit dilaporkan kepada manajemen yang relevan g. mengambil tindakan koreksi (correction) yang diperlukan dan tindakan korektif (corrective action) tanpa ditunda

h. Organisasi mewajibkan untuk memelihara informasi terdokumentasi sebagai bukti pelaksanaan program audit internal dan hasil audit

\section{B. Proses Bisnis Audit Internal}

Pada tahap ini pengolahan data dilanjutkan dengan melakukan penyusunan proses bisnis audit internal yang berdasarkan kepada requirement hasil integrasi standar ISO 9001:2015 klausul 9.2 dan standar ISO 14001:2015 klausul 9.2. Proses bisnis audit internal hasil benchmarking dan requirement hasil integrasi menjadi masukan pada tahap ini. Pada tahap ini proses bisnis audit internal hasil benchmarking dianalisis kesesuaiannya terhadap requirement. Apabila terdapat gap maka gap tersebut dihilangkan dengan melakukan perubahan, penambahan ataupun pengurangan aktivitas, ketentuan ataupun dokumen sehingga dihasilkan proses bisnis audit internal yang telah memenuhi requirement hasil integrasi ISO 9001:2015 klausul 9.2 dan standar ISO 14001:2015 klausul 9.2 yang terdapat pada Tabel I.

TABEL I

PROSES BISNIS AUDIT INTERNAL BERDASAR REQUIREMENTINTEGRASI

\begin{tabular}{|c|c|c|}
\hline No & Aktivitas & Pemilik Proses \\
\hline 1 & $\begin{array}{l}\text { Menetapkan rencana tahunan audit } \\
\text { internal }\end{array}$ & Wakil Manajemen \\
\hline 2 & Melakukan seleksi tim auditor & Wakil Manajemen \\
\hline 3 & $\begin{array}{l}\text { Memverifikasi tim audit berdasarkan } \\
\text { perencanaan wakil manajemen }\end{array}$ & Direktur \\
\hline 4 & Menetapkan jadwal audit internal & Tim audit \\
\hline 5 & Memeriksa jadwal audit & Direktur \\
\hline 6 & $\begin{array}{l}\text { Mendistribusikan jadwal audit } \\
\text { kepada auditee }\end{array}$ & Tim audit \\
\hline 7 & Menyiapkan kelengkapan audit & Tim audit \\
\hline 8 & $\begin{array}{l}\text { Melaksanakan audit dengan daftar } \\
\text { periksa audit yang telah dibuat }\end{array}$ & Tim audit \\
\hline 9 & Mencatat penemuan audit internal & Tim audit \\
\hline 10 & $\begin{array}{l}\text { Menyerahkan laporan } \\
\text { ketidaksesuaian kepada auditee }\end{array}$ & Tim audit \\
\hline 11 & $\begin{array}{l}\text { Auditee menganalisa dan meninjau } \\
\text { masalah }\end{array}$ & Auditee \\
\hline 12 & $\begin{array}{l}\text { Membuat tindakan perbaikan dan } \\
\text { pencegahan }\end{array}$ & Auditee \\
\hline 13 & $\begin{array}{l}\text { Follow up penetapan tindakan } \\
\text { perbaikan dan pencegahan }\end{array}$ & Tim audit \\
\hline 14 & $\begin{array}{l}\text { Tim audit memverifikasi } \\
\text { pengimplementasian tindakan } \\
\text { perbaikan dan pencegahan }\end{array}$ & Tim audit \\
\hline 15 & $\begin{array}{l}\text { Melakukan evaluasi efektivitas } \\
\text { penerapan sistem }\end{array}$ & Wakil Manajemen \\
\hline 16 & $\begin{array}{l}\text { Membuat laporan terhadap Top } \\
\text { Manajemen sebagai bahan rapat } \\
\text { tinjauan manajemen }\end{array}$ & Wakil Manajemen \\
\hline 17 & $\begin{array}{l}\text { Melakukan evaluasi program audit } \\
\text { yang telah dilaksanakan }\end{array}$ & $\begin{array}{c}\text { Tim audit \& } \\
\text { Wakil Manajemen }\end{array}$ \\
\hline 18 & $\begin{array}{l}\text { Wakil manajemen menyimpan dan } \\
\text { memelihara seluruh rekaman audit }\end{array}$ & Wakil Manajemen \\
\hline
\end{tabular}


Semua informasi mengenai proses bisnis, ketentuan dan dokumen yang ditentukan nantinya akan tersedia dalam bentuk SOP audit internal sehingga nantinya proses audit internal CV XYZ telah berdasarkan pada requirement yang harus dipenuhi.

\section{Hasil Risk Assessment}

Proses risk assessment diawali dengan identifikasi risiko pada proses bisnis audit internal yang telah disusun berdasarkan dengan requirement, kemudian dilakukan brainstorming untuk dapat mengidentifikasi hazard dan risiko yang mungkin muncul pada setiap aktivitas dalam proses audit internal tersebut. Risiko yang didapatkan melalui analisis dan brainstorming tersebut kemudian diverifikasi dengan melakukan wawancara terhadap pelaku proses di perusahaan partner benchmark yang sudah mengimplementasikan proses audit internal.

Data risiko yang telah teridentifikasi dari setiap aktivitas yang ada pada proses audit internal dinilai untuk mengetahui seberapa sering risiko tersebut terjadi dan seberapa besar dampak yang ditimbulkan risiko tersebut terhadap proses audit internal yang berjalan diperusahaan. Penilaian dilakukan oleh process owner di perusahaan partner benchmark melalui proses wawancara dimana pada proses wawancara tersebut dibantu dengan form daftar risiko yang berisi daftar risiko, kolom likelihood dan severity. Penilaian risiko dilakukan terhadap perusahaan partner benchmark karena pada CV XYZ, SOP audit internal yang dimiliki belum diterapkan sehingga penilaian risiko proses audit internal valid karena dilakukan oleh perusahaan partner benchmark yang telah melakukan proses audit internal secara continue. Pengisian likelihood dan severity menggunakan skala 1-5 dengan berdasarkan pada referensi APES 352 Risk Management for Firm yang didesain dengan berpedoman kepada ISO 31000:2019 standar untuk risk management yang ditunjukan pada Tabel II dan Tabel III [8].

TABEL II

SKALA PROBABILITAS RISIKO

\begin{tabular}{|c|l|c|}
\hline Likelihood & Probabilitas Terjadinya Risiko & $\begin{array}{c}\text { Skala } \\
\text { Numerik }\end{array}$ \\
\hline Rare & $\begin{array}{l}\text { Probabilitas terjadinya risiko } \\
\text { kurang dari 5\%, hampir tidak } \\
\text { pernah terjadi dalam 5 tahun } \\
\text { pelaksanaan }\end{array}$ & 1 \\
\hline Unlikely & $\begin{array}{l}\text { Probabilitas terjadinya risiko antara } \\
5 \%-10 \%, \text { jarang terjadi, 1 kali } \\
\text { dalam 5 tahun terakhir } \\
\text { pelaksanaan }\end{array}$ & 2 \\
\hline Possible & $\begin{array}{l}\text { Probabilitas terjadinya risiko antara } \\
10 \%-50 \% \text {, terjadi 2 kali dalam 5 } \\
\text { tahun terakhir pelaksanaan }\end{array}$ & 3 \\
\hline Likely & $\begin{array}{l}\text { Probabilitas terjadinya risiko antara } \\
50 \%-90 \% \text {, terjadi 1 kali dalam 2 } \\
\text { tahun terakhir pelaksanaan }\end{array}$ & 4 \\
\hline Almost & $\begin{array}{l}\text { Probabilitas terjadinya }>90 \%, \\
\text { terjadi setiap kali pelaksanaan }\end{array}$ & 5 \\
Certain & & \\
\hline
\end{tabular}

Kemungkinan (likelihood) sering dinyatakan dengan probabilitas yaitu peluang terjadinya sebuah risiko dapat terjadi. Sedangkan severity atau tingkat dampak suatu risiko merupakan besarnya dampak risiko yang mungkin diterima oleh perusahaan apabila sebuah risiko terjadi.
Skala pengukuran tingkat probabilitas (likelihood) dan tingkat dampak (severity) yang digunakan pada penelitian ini adalah skala pengkuran ordinal yaitu skala pengukuran dengan mengurutkan tingkat "pentingnya" kejadian dengan memberikan uraian untuk memperjelas mengapa suatu kelompok lebih tinggi peringkatnya dari kelompok yang lain pada setiap peringkat [9].

TABEL III

SKALADAMPAK RISIKO

\begin{tabular}{|c|l|c|}
\hline Severity & \multicolumn{1}{|c|}{ Deskripsi } & $\begin{array}{c}\text { Skala } \\
\text { Numerik }\end{array}$ \\
\hline Insignificant & $\begin{array}{l}\text { Terdapat kerugian tetapi tidak secara } \\
\text { materi, kontrol dan prosedur eksisting } \\
\text { dapat mengatasi peristiwa tersebut }\end{array}$ & 1 \\
\hline Minor & $\begin{array}{l}\text { Peristiwa dengan beberapa } \\
\text { konsekuensi yang mudah diatasi }\end{array}$ & 2 \\
\hline Moderate & $\begin{array}{l}\text { Peristiwa yang cukup terlihat pada } \\
\text { perusahaan, dan beberapa tujuan bisnis } \\
\text { perusahaan tidak tercapai }\end{array}$ & 3 \\
\hline Major & $\begin{array}{l}\text { Peristiwa yang mengakibatkan } \\
\text { dampak material terhadap perusahaan, } \\
\text { key business objective tidak tercapai. }\end{array}$ & 4 \\
\hline Catasthropic & $\begin{array}{l}\text { Peristiwa atau keadaan dengan yang } \\
\text { berpotensi menimbulkan dampak yang } \\
\text { besar untuk bisnis }\end{array}$ & 5 \\
\hline
\end{tabular}

Hasil penilaian risiko pada tahap analisis risiko selanjutnya dievaluasi menggunakan risk rating untuk mengetahui risiko yang menjadi prioritas untuk segera ditangani karena frekuensi terjadinya yang sangat sering dan dampak yang ditimbulkan besar terhadap kelansungan perusahaan. Proses evaluasi risiko membantu dalam proses pengambilan keputusan yang dilakukan berdasarkan hasil dari analisis risiko mengenai risiko mana yang diprioritaskan untuk ditangani. Pada proses evaluasi ini akan didapatkan risiko yang harus diprioritaskan untuk segera ditangani berdasarkan hasil penilaian tingkat probabilitas dan dampak dari risiko yang telah dilakukan berdasarkan risk rating matrix pada Gambar 1.

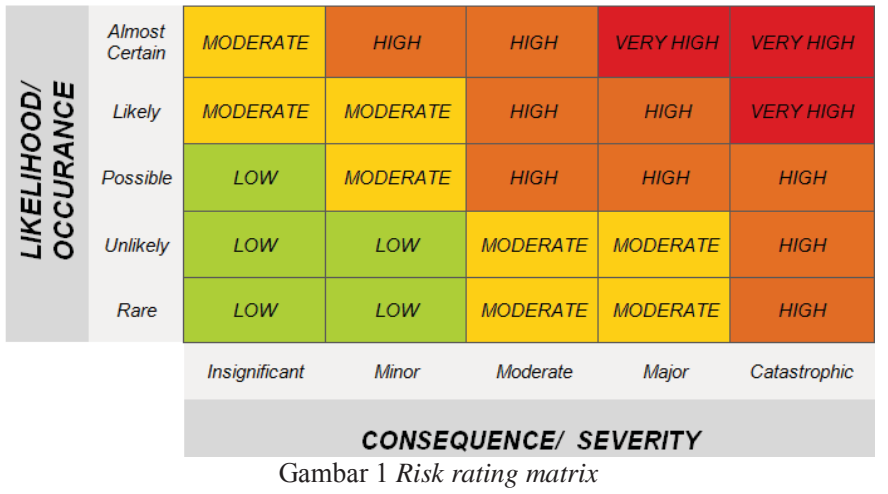

Pada evaluasi risiko ini dilakukan pemetaan risiko dengan membagi risiko kedalam beberapa level risiko yaitu sangat tinggi, tinggi, menengah, dan rendah. Risiko dengan level tinggi memerlukan perhatian dan dukungan dari manajemen puncak, rencana, indakan dan akuntabilitas perlakuan risiko harus jelas dan terukur [9].

Berdasarkan hasil evaluasi risiko terdapat 4 risiko yang perlu segera dilaksanakan karena termasuk ke dalam kategori risiko dengan 
level tinggi. Risiko dengan level tersebut dihasilkan dari tingkat frekuensi terjadinya risiko yang tinggi dan tingkat dampak yang besar terhadap perusahaan. Penanganan risiko yang efektif diperlukan dalam upaya continuous improvement di perusahaan.

Penanganan risiko tersebut diawali dengan proses mengidentifikasi penyebab risiko dapat terjadi dengan menggunakan fishbone. Melalui identifikasi akar permasalahan diharapkan akan didapatkan tindakan penanganan risiko yang efektif sehingga dapat memperkecil kemungkinan risiko tersebut terjadi. Upaya penanganan risiko tersebut akan menjadi masukan dalam proses perancangan SOP audit internal sehingga SOP yang dirancang akan dapat mengantisipasi risiko terjadi sehingga mengurangi kemungkinan proses audit internal mengalami kegagalan sehingga tindakan korektif diperlukan diakhir proses.

Hasil dari proses risk assessment terangkum dalam sebuah risk register yang didalamnya tercantum daftar risiko beserta dengan penyebab, dampak, kontrol yang yang telah dilakukan, hasil penilaian likelihood dan severity risiko serta penanganan risiko yang terdiri dari program yang akan dilakukan untuk penanggulangan risiko dan penanggung jawab program penanganan risiko. Tindakan penanganan risiko pada risk register selanjutnya akan menjadi input dalam penyusunan proses bisnis audit internal. Sehingga proses bisnis audit internal yang nantinya dihasilkan akan dapat mencegah risiko yang mungkin muncul khususnya pada risiko dengan level tinggi.

TABEL IV

RISKREGISTER PROSES AUDIT INTERNAL

\begin{tabular}{|c|c|c|c|c|c|c|}
\hline No. & Risiko & $L^{*}$ & $S^{*}$ & $R^{*}$ & Program Penanganan & $\begin{array}{c}\text { Penanggung } \\
\text { Jawab }\end{array}$ \\
\hline 1 & $\begin{array}{l}\text { Tim audit tidak kompeten } \\
\text { untuk melakukan audit } \\
\text { (dalam segi kemampuan } \\
\text { dan objektifitas) }\end{array}$ & 3 & 3 & $H$ & $\begin{array}{l}\text { Eliminasi/ Mitigasi : } \\
\text { 1. Penetapan ketentuan Tim audit untuk tidak mengaudit } \\
\text { unitnya sendiri }\end{array}$ & $\begin{array}{l}\text { Wakil } \\
\text { Manajemen dan } \\
\text { Tim Audit }\end{array}$ \\
\hline 2 & $\begin{array}{l}\text { Ketidaksiapan auditee } \\
\text { dalam pelaksanaan audit } \\
\text { internal }\end{array}$ & 3 & 3 & $H$ & $\begin{array}{l}\text { Eliminasi/ Mitigasi : 1. Penetapan ketentuan bahwa } \\
\text { wakil manajemen mensosialisasikan rencana tahunan } \\
\text { audit di awal tahun, } \\
\text { 2. Pemberitahuan jadwal audit selambat-lambatnya } 1 \\
\text { minggu sebelum pelaksanaan audit, } \\
\text { 3. Follow up persiapan audit oleh penanggung jawab } \\
\text { setiap unit, } \\
\text { 4. pembuatan report mingguan agar tidak menumpuk di } \\
\text { akhir }\end{array}$ & $\begin{array}{l}\text { Wakil } \\
\text { Manajemen dan } \\
\text { Auditee }\end{array}$ \\
\hline 3 & $\begin{array}{l}\text { Tindakan koreksi yang } \\
\text { ditetapkan tidak efektif }\end{array}$ & 3 & 3 & $H$ & $\begin{array}{l}\text { Eliminasi/ Mitigasi : 1. Verifikasi tindakan koreksi yang } \\
\text { ditetapkan oleh auditee oleh tim audit, 2. Penggunaan } \\
\text { tools dalam upaya identifikasi penyebab masalah agar } \\
\text { tindakan koreksi yang dihasilkan efektif }\end{array}$ & $\begin{array}{l}\text { Tim Audit dan } \\
\text { Auditee }\end{array}$ \\
\hline 4 & $\begin{array}{l}\text { Tindakan koreksi tidak } \\
\text { diimplementasikan }\end{array}$ & 3 & 3 & $H$ & $\begin{array}{l}\text { Eliminasi/ Mitigasi : 1. Pemantauan secara berkala } \\
\text { (pemantauan pelaksanaan yang dilakukan } 2 \text { tahap, } \\
\text { pertama untuk mengecek pengimplementasian tindakan } \\
\text { koreksi sesuai dengan yang ditetapkan dan kedua untuk } \\
\text { mengecek konsistensi), } \\
\text { 2. Sosialisasi tindakan koreksi oleh penanggung jawab } \\
\text { unit }\end{array}$ & $\begin{array}{l}\text { Tim Audit dan } \\
\text { Auditee }\end{array}$ \\
\hline
\end{tabular}

\section{$* L=$ Likelihood $\quad * S=$ Severity $\quad * R=$ Rating}

D. SOP Audit Internal Berdasarkan Requirement Integrasi dan telah Mempertimbangkan Risiko

Pada tahap ini dihasilkan SOP audit internal usulan berdasarkan integrasi ISO 9001:2015 klausul 9.2 dan ISO 14001:2015 klausul 9.2 dengan mempertimbangkan risiko yang telah terverifikasi oleh $\mathrm{CV}$ XYZ. SOP audit internal yang dihasilkan ini diharapkan dapat menjamin proses audit internal dilaksanakan di CV XYZ dalam upaya perbaikan sistem manajemen mutu dan lingkungan yang berkelanjutan. Usulan prosedur audit internal pada SOP audit internal disajikan seperti pada lampiran penelitian ini. Perancangan SOP audit internal usulan disertai dengan perancangan struktur organisasi yang dapat mengatasi seluruh proses-proses penjaminan mutu, dimana selami ini dilakukan oleh wakil manajemen yang menempel pada fungsi lain dan tidak definisikan secara strukutural di struktur organisasi yang dapat mengakibatkan proses audit internal tidak terlaksana secara efekif karena tidak ada fungsi khusus yang menanganinya. Pada strukturorganisasi baru dibuat fungsi wakil manajemen yang terdiri dari:

1. Bagian audit bertugas dan bertanggung jawab terhadap pelaksanaan audit di perusahaan dari tahap perencanaan hingga pelaporan hasil audit sehingga pelaksanaan audit diperusahaan dapat terlaksana secara efektif.

2. Bagian pengendali mutu dan lingkungan bertugas melakukan analisis dan evaluasi baik hasil audit, hasil pemantauan dan pengukuran, dan hasil ketidaksesuaian dan tindakan perbaikan. Hasil analisis dan evaluasi tersebut dijadikan sebagai bahan rapat tinjauan majemen yang dilakukan oleh wakil manajemen sehingga pelaksanaan rapat tinjauan manajemen diperusahaan dapat terlaksana secara efektif. 
3. Bagian pengendali informasi terdokumentasi bertugas untuk memelihara informasi terdokumentasi pada proses-proses yang dilakukan perusahaan sehingga informasi penting perusahaan didokumentasikan secara sistematis dan mudah dicari pada saat diperlukan.

SOP audit internal yang dihasilkan pada penelitian ini telah melalui proses verifikasi dimana CV XYZ menyatakan bahwa SOP audit internal yang dirancang telah sesuai dengan kebutuhan perusahaan dan dapat mendukung perbaikan SMM dan SMM secara berkelanjutan di perusahaan.

Perancangan SOP audit internal yang disertai dengan perancangan struktur organisasi dengan menambahkan fungsi baru untuk menjamin pelaksanaan audit internal menjadikan SOP audit internal yang diusulkan dikatakan telah sesuai dengan kondisi perusahaan karena telah mempertimbangkan faktor struktur organisasi yang ada saat ini. Fungsi baru yang ditambahkan adalah fungsi wakil manajemen yang terdiri bagian pengendali mutu dan lingkungan, bagian audit dan bagian pengendali informasi tedokumentasi. Penambahan fungsi tersebut pada struktur organisasi akan mendukung pelaksanaan audit internal sehingga penjaminan mutu dan lingkungan di CV XYZ berlangsung secara efektif.

Berdasarkan hasil analisis SOP audit internal usulan dengan requirement hasil integrasi dapat disimpulkan bahwa SOP yang dibuat telah memenuhi semua requirement audit internal yang berdasarkan pada standar ISO 9001:2015 Klausul 9.2 dan ISO 9001:2015 Klausul 9.2. Requirement audit internal terintegrasi yang mensyaratkan CV XYZ untuk melakukan audit internal dalam selang waktu terencana untuk meninjau kesesuaian SMM dan SML terhadap persyaratan yang ditetapkan perusahaan serta standar ISO 9001:2015 dan ISO 14001:2015 dan juga mensyaratkan untuk membuat program audit yang meliputi tahap perencanaan, persiapan, pelaksanaan hingga pelaporan hasil audit serta penyimpanan informasi terdokumentasi audit dimana pelaksanaan audit dilakukan secara objektif dan penindaklanjutan hasil audit dilakukan dengan tanpa ditunda telah dapat dipenuhi SOP audit internal usulan melalui pendefinisian aktivitas yang sesuai dengan requirement tersebut dan penambahan ketentuan yang dapat memastikan requirement tersebut terpenuhi.

SOP audit internal yang dihasilkan pun telah mempertimbangkan risiko yang mengakibatkan kegagalan pencapaian sasaran audit internal atau kegagalan proses audit internal seperti yang terjadi sekarang ini. SOP audit internal telah dilengkapi dengan kontrol yang digunakan untuk mengantisipasi terjadinya risiko yang tidak dimiliki oleh proses audit internal sebelumnya melalui penetapan tenggang waktu pelaksanaan aktivitas-akivitas pada proses audit internal. SOP audit internal usulan dirancang berdasarkan risk register guna mempertimbangkan risiko yang akan muncul alam proses audit internal agar dapat diantisipasi. SOP audit internal usulan telah dapat mengantisipasi risiko yang telah dievaluasi dan termasuk kepada kategori high.

Ditinjau dari keefektifan, SOP audit internal usulan lebih efektif jika dibandingkan dengan SOP audit internal eksisting. SOP yang dibuat telah dapat menjamin tujuan audit internal adalah untuk meninjau kesesuaian antara perencanaan sistem manajemen terintegrasi dengan implementasinya dan meninjau efektifitas SMM dan SML perusahaan dalam upaya perbaikan berkelanjutan. Hasil dari peninjauan kesesuaian tersebut nantinya akan diperbaiki hingga kemudian dilaporkan kepada bagian pengendali mutu dan lingkungan untuk dianalisis yang akan menjadi bahan rapat tinjauan manajemen agar dapat terus dilakukan upaya perbaikan berkelanjutan pada perusahaan

Efektifitas SOP ini dikatakan lebih besar karena SOP ini telah mempertimbangkan proses audit internal yang sudah dapat terimplementasi diperusahaan partner benchmark, keterkaitan antar proses kemudian telah dianalisis pula risiko yang dapat mengakibatkan kegagalan proses sehingga akan lebih efektif jika dibandingkan dengan SOP audit internal hasil penelitian terdahulu.

\section{KESIIMPULAN}

Berdasarkan penelitian yang telah dilakukan didapatkan requirement audit internal terintegrasi berdasarkan ISO 9001:2015 Klausul 9.2 dan ISO 14001:2015, risk register proses audit internal CV XYZ dan SOP audit internal berdasarkan requirement terintegrasi dengan telah mempertimbangkan risiko. Hasil integrasi requirement kemudian dijadikan acuan untuk merancang proses bisnis audit internal yang telah didapatkan menggunakan metode benchmarking dengan perusahaan partner benchmark menjadi proses bisnis audit internal yang sesuai dengan requirement integrasi. Proses bisnis yang telah sesuai dengan requirement integrasi tersebut selanjutnya ditentukan risikonya melalui risk assessment sehingga menghasilkan risk register yang didalamnya terdapat penanganan untuk masingmasing risiko yang berkategori high. Proses bisnis berdasarkan requirement dan risk register kemudian menjadi input pada proses perancangan sehingga dihasilkan SOP audit internal berdasarkan ISO 9001:2015 Klausul 9.2 dan ISO 14001:2015 Klausul 9.2 dengan mempertimbangkan risiko. Hasil penelitian tersebut diharapkan dapat menjamin terlaksananya proses audit internal di CV XYZ secara efektif dan continue sehingga penjaminan mutu dan lingkungan dapat berlangsung untuk mendukung perbaikan berkelanjutan di CV XYZ

\section{DAFTAR PUSTAKA}

[1] Gaspersz, Vincent. 2013. All-in-one Bundle of ISO 9001, ISO 14001, OHSAS 18001, ISO 22000, ISO 26000, ISO 28000, ISO 31000, ISO 13053-1, ISO 19011 and Continual Improvement. Bogor: Tri-Al-Bros Publishing.

[2] Fatharani, Hasna. 2014. Perancangan Standard Operating Procedure (SOP) untuk memenuhi Requirement ISO Berdasarkan Integrasi ISO 9001:2008 dan ISO 14001:2004 (Klausul 4.4.3, 4.4.5, 4.4.6, 4.4.7, 4.5.1, 4.5.4, 4.5.5, 4.6) di CV XYZ dengan Metode Business Process Improvement.

[3] ISO. 2004. ISO 14001:2015 Environmental Management Systems - Requirements with Guidance for Use. Jenewa, Swiss: ISO.

[4] ISO. 2008. ISO 9001:2015 Quality Management Systems - Requirements. Jenewa, Swiss: ISO.

[5] Khalidah, Hana. 2014. Perancangan Standard Operating Procedure (SOP) dan Kebijakan Lingkungan Untuk Memenuhi Requirement ISO Berdasarkan Integrasi ISO 9001:2008 dan ISO 14001:2004 (Klausul 4.1, 4.2, 4.3.1, 4.3.2, 4.3.3, 4.4.1, 4.4.2, 4.4.4, 4.5.2, 4.5.3) di CV. XYZ dengan Metode Business Process Improvement. 
[6] Talcha, Fadhila. 2014. Perancangan Standard Operating Procedure (SOP) untuk memenuhi Requirement Integrasi ISO 9001:2008 dengan OHSAS 18001:2007 (Klausul 4.4.5, 4.4.6, 4.4.7, 4.5.4, dan 4.5.5) di CV. XYZ Menggunakan Metode Business Process Improvement.

[7] De Toro, I dan A Tenner. 1997. Process Redesign. Canada: AddISOn Wesley Longman Inc.
[8] https://survey.charteredaccountants.com.au/risk_manage ment/default.aspx, diakses 26 Maret 2016.

[9] Susilo, Leo J dan Victor Riwu Kaho, 2014. Panduan Manajemen Risiko Berbasis ISO 31000 Industri NonPerbankan. Jakarta: PPM. 
LAMPIRAN

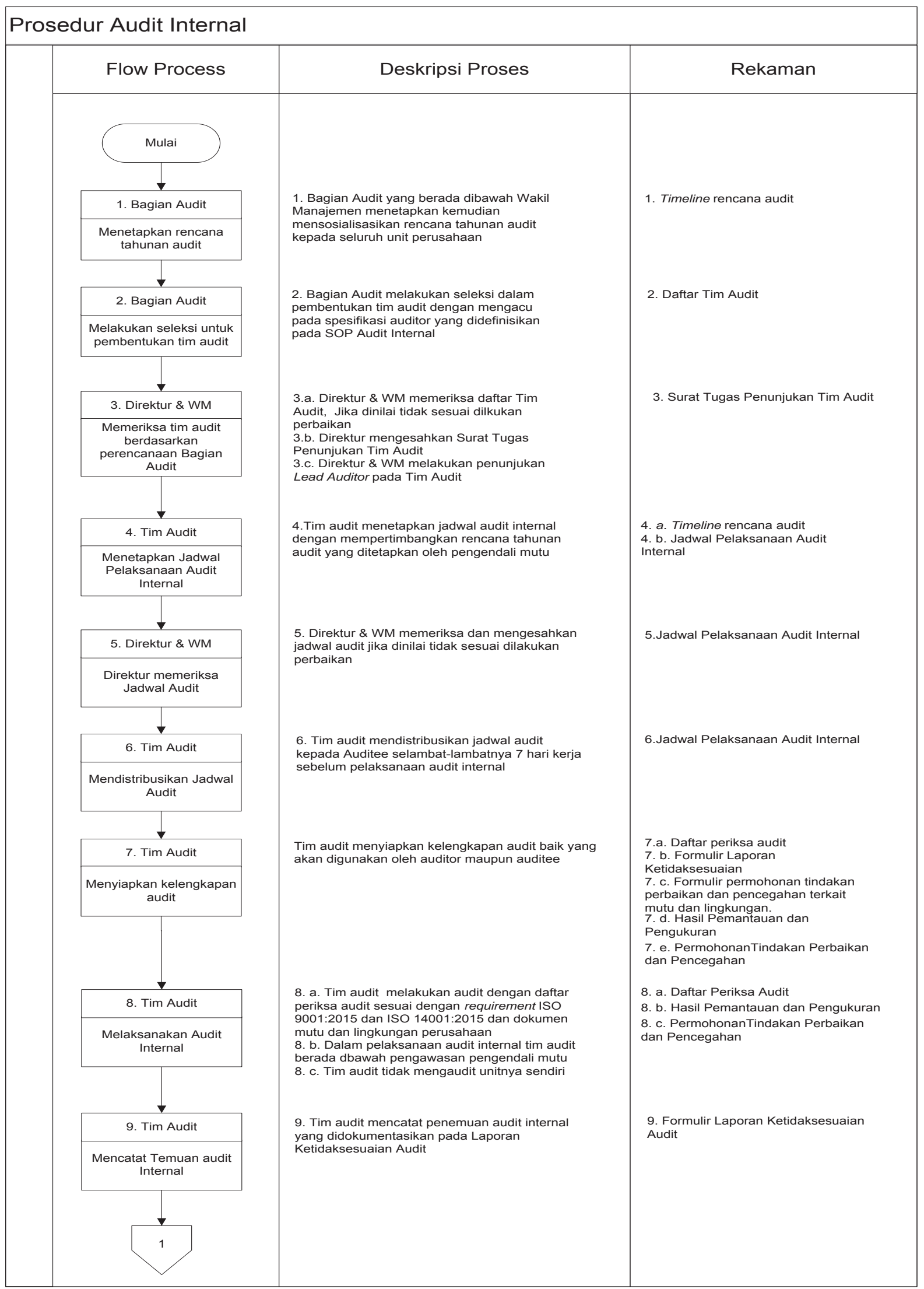




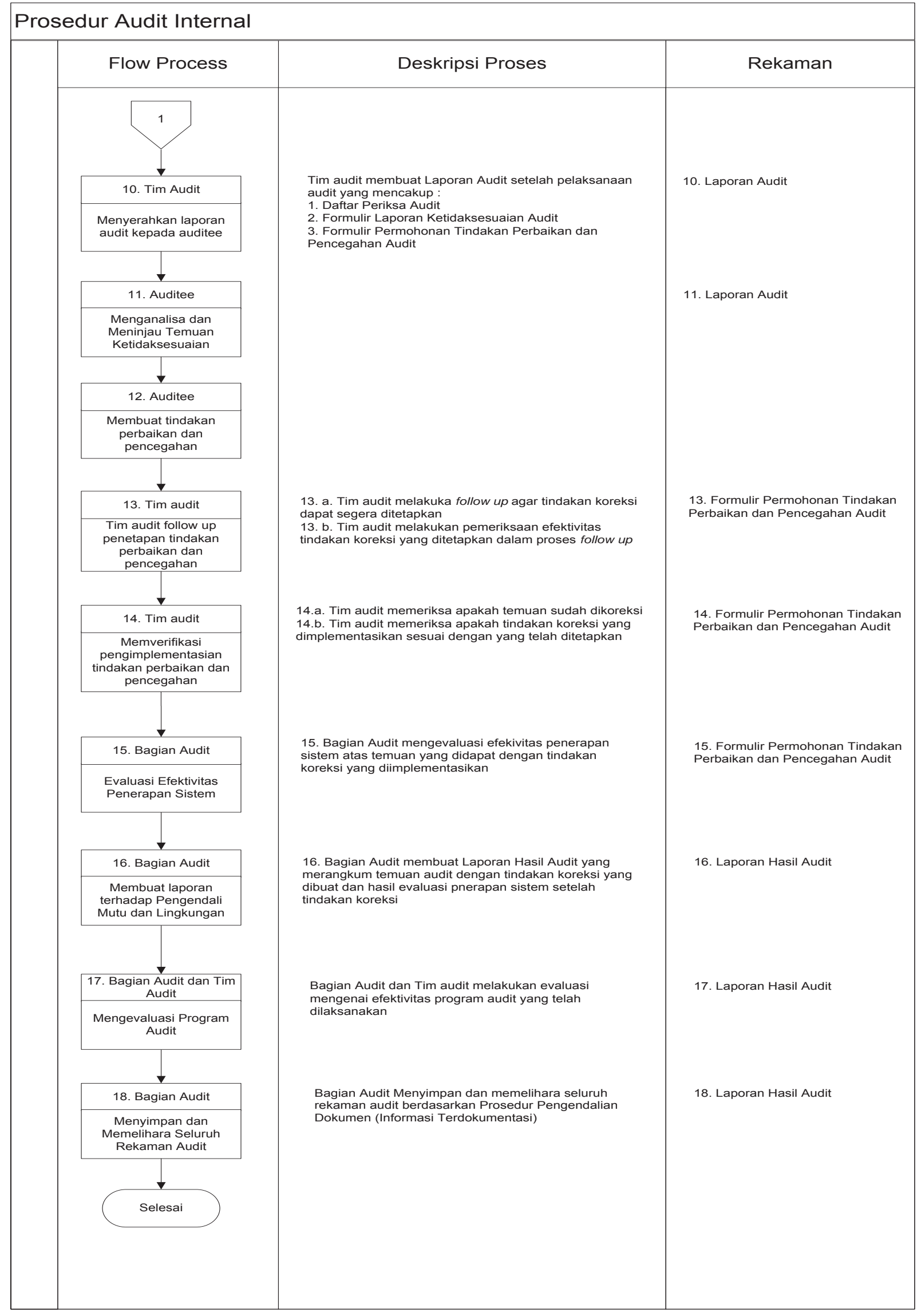

